\title{
Ginseng-Lactobacillus Ferment Exerts Synergistic Anti-Melanogenic Effects with Low Doses of Niacinamide In Vitro
}

\author{
Huey-Chun Huang ${ }^{1}$, JI-Ying Lu ${ }^{3}$, Wen-Yang Chuang ${ }^{2}$, Tsong-Min Chang ${ }^{3 *}$ \\ ${ }^{1}$ Department of Medical Laboratory Science and Biotechnology, China Medical University, Taiwan \\ ${ }^{2}$ SIKI Biological R\&D Center, Suzhou Industrial Park, China
}

${ }^{3}$ Department of Applied Cosmetology, Hungkuang University, Taiwan

*Corresponding author: Tsong-Min Chang, Department of Applied Cosmetology, Hungkuang University, Taiwan

\begin{abstract}
ARTICLE INFO
Received: 幽 February 28, 2020

Published: March 04, 2020

Citation: Huey-Chun H, JI-Ying L, WenYang C, Tsong-Min C. Ginseng-Lactobacillus Ferment Exerts Synergistic Anti-Melanogenic Effects with Low Doses of Niacinamide In Vitro. Biomed J Sci \& Tech Res 26(2)-2020. BJSTR. MS.ID.004323.
\end{abstract}

Abbreviations: GLF: Ginseng Lactobacillus Ferment; L-DOPA: L-tyrosineto 3-4-dihydroxy phenylalanine; CFU: Colony-Forming Units; BCRC: Bioresource Collection and Research Center; PVDF: Polyvinylidene Fluoride; MOE: Ministry of Education

\begin{abstract}
The fermentation of ginseng increases the efficacy and bioavailability of ginseng. However, the ginsenoside $\mathrm{Rb} 2$-specific molecular mechanism in the ginseng lactobacillus ferment (GLF) with niacinamide has not been elucidated in murine B16F10 melanoma cells. In this study, we investigated the possible synergistic anti-melanogenic effects of the GLF or ginsenoside $\mathrm{Rb} 2$ and low dose of niacinamide $(100 \mu \mathrm{M})$ on B16F10 cells and explored the potential synergistic role of anti-melanogenesis. Cell proliferation analysis was evaluated by MTT assay. The effects on melanogenesis were evaluated spectrophotometrically. The expression levels of melanogenesis-related proteins were analyzed by Western blot. Combining of GLF $(0.75 \mathrm{mg} / \mathrm{mL})$ or ginsenoside $\mathrm{Rb} 2(10 \mu \mathrm{M})$ with of niacinamide $(100$ $\mu \mathrm{M})$ significantly decreased cellular melanin content. In the western blotting assay, the combination of GLF or Rb 2 and niacinamide decreased the protein expression levels of tyrosinase, tyrosinase-related protein 1 (TRP-1) and PMEL17 compared with control alone. The results demonstrated that ginsenoside $\mathrm{Rb} 2$ in GLF may play a role in the synergistic anti-melanogenic effects of GLF with niacinamide on murine melanoma cells. The findings suggested GLF or ginsenoside Rb2 can be added into skin whitening skin care product with niacinamide to enhance its anti-melanogenesis effects.
\end{abstract}

Keywords: Ginseng Lactobacillus Ferment; Ginsenoside; Rb 2; Niacinamide; Tyrosinase; Melanin

\section{Introduction}

In the field of research on skin health, much effort has focused on developing functional skin-whitening products for people with unwanted pigments. Hyperpigmentation of the skin is a result of abnormal accumulation of melanin, a skin pigment that is essential for photoprotection of the human body against ultraviolet (UV) hurts. Previous studies have reported that the first steps of melanogenesis pathway in humans are the hydroxylation of L-tyrosine to 3-4-dihydroxy phenylalanine (L-DOPA) and the oxidation of L-DOPA to o-dopaquinone [1]. Tyrosinase is known as the rate-limiting enzyme and catalyzes both of the reactions in melanogenesis. Antioxidants, such as arbutin or kojic acid [2], may inhibit these oxidation steps and have been used in the treatment of hyperpigmentation [3]. Niacinamide (also known as nicotinamide, 3-pyridinecarboxamide) is the amide of niacin (vitamin B3) that is a physiologically active component in various cosmetics and medicines. Niacinamide is well tolerated by the skin, in contrast to other common forms of this vitamin family (e.g. nicotinic acid and its esters), which often induce uncomfortable skin flushing reactions [4]. It has been reported that oral niacinamide (or niacin) could prevent the development of insulin-dependent diabetes mellitus [5].

Several reports suggest that niacinamide may exert various effects on the skin: it acts as an anti-inflammatory agent in acne 
[6], as an antioxidant [7], prevents photo-carcinogenesis and photo-immunosuppression [8], and increases intercellular lipid synthesis [9]. The biological activities of niacinamide also include antimicrobial, photo-protection, lighting, and anti-pruritus [10]. Moreover, niacinamide has been reported to promote the repair of DNA damage induced by UV in keratinocytes [11,12]. Previous study has been demonstrated that niacinamide affect pigmentation that works by inhibiting melanosome transfer from melanocytes to keratinocytes [13]. Also, several benefits in terms of improved appearance of photo-aged skin including redness and wrinkles, reduced sebum production and improved barrier function have been described by topical usage of niacinamide $[14,15]$. As a typical medicine for treating hyperpigmentation disorders, niacinamide blocks the melanosome migration between melanocytes and keratinocytes and suppresses skin pigmentation [16]. Panax ginseng C.A. Meyer has been used in traditional folk medicine in Asian countries.

The P. ginseng fruits have pharmacological effects such as antidiabetic [17], anticancer [18,19], antioxidant [20, 21], antiaging [22], and antiallergic effects [23]. Furthermore, ginsenoside Rb2 (Gin-Rb2) from P. ginseng was reported to have several biological activities, including radioprotective [24], antidiabetic [25], antitumor [26], and antivirus [27] effects. Previous study has reported that the Gin-Rb2 could decrease tyrosinase and MITF protein expression in melan-a cells. In addition, Gin-Rb2 presented inhibition of the body pigmentation in the zebrafish in vivo system [28]. Here, we aim to investigate the anti-melanogenic effects of the compatibility of ginseng lactobacillus ferment or ginsenoside $\mathrm{Rb} 2$ and niacinamde on a B16F10 murine melanoma cell model.

\section{Materials and Methods}

The antibodies were from Santa Cruz Biotech (Santa Cruz, CA, USA) and the ECL reagent was from Millipore (Burlington, MA, USA). All chemical reagents including $\alpha$-MSH, arbutin, and kojic acid were purchased from Sigma-Aldrich Chemical Co. (St. Louis, MO, USA). Lactobacillus plantarum (BCRC10069) was cultivated in lactobacilli MRS (de Man, Rogosa, Sharpe) broth (Becton, Dickinson and Company, Sparks, MD, USA) at $37^{\circ} \mathrm{C}$, for $12 \mathrm{~h}$, and the activated culture was inoculated into MRS broth at $37^{\circ} \mathrm{C}$, for $12 \mathrm{~h}$, twice. One gram of Panax ginseng (C. A. Meyer) was added to $99 \mathrm{~mL}$ distilled water and then sterilized at $121^{\circ} \mathrm{C}$ for $15 \mathrm{~min}$. The ginseng solution ( $\mathrm{pH}$ 6.5) was inoculated with L. plantarum culture $\left[1 \times 10^{8}\right.$ colony-forming units (CFU)/mL] to a final concentration of $1 \%$ (v/v) and fermented at $37^{\circ} \mathrm{C}$ for $24 \mathrm{~h}$. Samples were collected for analysis at $0 \mathrm{~h}, 4 \mathrm{~h}, 8 \mathrm{~h}, 12 \mathrm{~h}, 16 \mathrm{~h}, 20 \mathrm{~h}$, and $24 \mathrm{~h}$. The viable cells of L. plantarum were counted on MRS agar using the plate counting method [29], and the $\mathrm{pH}$ and titratable acidity during fermentation were determined using a $\mathrm{pH}$ meter (Microprocessor Benchtop $\mathrm{pH}$ Meter Model SP-2300, Suntex, Taiwan) and following the method described by Collins, et al. [30].
The Ultra Performance Liquid Chromatography (UPLC) instrumental analysis was performed by a Waters ACQUITY UPLC system (Waters, Millford, MA, USA) composed of a binary solvent manager, sample manager and photo diode array detector (PDA). The chromatographic separation was accomplished on an ACQUITY BEH C18 column (100 mm×2.1 mm, $1.7 \mu \mathrm{m}$; Waters). The column temperature was $40^{\circ} \mathrm{C}$. The binary gradient elution system consisted of $0.001 \%$ phosphoric acid in water (A) and $0.001 \%$ phosphoric acid in acetonitrile (B). The separation was achieved using the following gradient program: 0-0.5 $\mathrm{min}(15 \%$ B), $14.5 \min (30 \%$ B), $15.5 \min (32 \%$ B), $18.5 \min (38 \%$ B), 24.0 $\min (43 \%$ B), $27.0 \min (55 \%$ B), 27.0-31.0 min (55\% B), $35.0 \mathrm{~min}$ $(70 \% \mathrm{~B}), 38.0 \mathrm{~min}(90 \% \mathrm{~B}), 38.1 \mathrm{~min}(15 \% \mathrm{~B})$, and 38.1-43.0 $\mathrm{min}$ $(15 \% \mathrm{~B})$. The flow rate was set at $0.6 \mathrm{~mL} / \mathrm{min}$ and the sample injection volume was $2.0 \mu \mathrm{L}$. The ginsenosides were detected by PDA at 203 nm [31]. The B16F10 (ATCC CRL-6475; BCRC60031) murine melanoma cells were obtained from the Bioresource Collection and Research Center (BCRC), Taiwan. The cells were maintained in the Dulbecco's Modified Eagle Medium (DMEM) (HyClone, Logan, UT) that was supplemented with $10 \%$ fetal bovine serum and penicillin/streptomycin $(100 \mathrm{IU} / 50 \mu \mathrm{g} / \mathrm{mL})$ at $37^{\circ} \mathrm{C}$, $5 \% \mathrm{CO}_{2}$ in a humidified incubator. The 3-(4, 5-dimethylthiazol-2yl)-2, 5-diphenyltetrazolium bromide (MTT) method was used to measure cell viability [32].

The cells were exposed to GLF $(0.75 \mathrm{mg} / \mathrm{mL})$, ginsenoside $\mathrm{Rb} 2(10 \mu \mathrm{M})$ or niacinamide $(100 \mu \mathrm{M})$ for $24 \mathrm{~h}$, then the MTT solution was added to the wells. The insoluble derivative of MTT that was produced by intracellular dehydrogenase was solubilized with DMSO-ethanol (1:1 mixture solution). The absorbance of the wells at $570 \mathrm{~nm}$ was read using a microplate reader. The results are expressed as percent viability relative to control. Each sample was measured in triplicate, and each experiment was repeated at least three times. The mushroom tyrosinase activity assays were conducted as previously described [33]. In brief, the aqueous solution of mushroom tyrosinase (200 units/10 $\mu \mathrm{L}$ ) was added to a 96-well microplate to result in a mixture with a total volume of $200 \mu \mathrm{L}$ that contained L-DOPA ( $5 \mathrm{mM})$, which was dissolved in phosphate-buffered saline (PBS, $50 \mathrm{mM}, \mathrm{pH}$ 6.8), and GLF (0.75 mg/ $\mathrm{mL})$, ginsenoside $\mathrm{Rb} 2(10 \mu \mathrm{M})$ or niacinamide $(100 \mu \mathrm{M})$, arbutin $(2$ $\mathrm{mM})$ or kojic acid $(200 \mu \mathrm{M})$ were then added into the mixture. The assay mixture was incubated at $37^{\circ} \mathrm{C}$ for $30 \mathrm{~min}$, and the absorbance of the dopachrome that was produced was measured at $490 \mathrm{~nm}$. The intracellular melanin content in the B16F10 melanoma cells was measured as described by Tsuboi, et al. [34].

The cells were treated with $\alpha$-MSH (100 nM) for $24 \mathrm{~h}$, and the melanin content was determined after treatment with either GLF $(0.75 \mathrm{mg} / \mathrm{mL})$, ginsenoside $\mathrm{Rb} 2(10 \mu \mathrm{M})$ or niacinamide $(100 \mu \mathrm{M})$ or arbutin ( $2 \mathrm{mM}$ ) for an additional $24 \mathrm{~h}$. After the treatment, the cell pellets containing a known number of cells were solubilized in $1 \mathrm{~N} \mathrm{NaOH}$ at $60^{\circ} \mathrm{C}$ for $60 \mathrm{~min}$. The melanin content was assayed 
at $405 \mathrm{~nm}$. The intracellular tyrosinase activity of the B16F10 cells was determined as described previously [35]. The cells were treated with $\alpha$-MSH (100 nM) for $24 \mathrm{~h}$ and then with GLF $(0.75 \mathrm{mg} / \mathrm{mL})$, ginsenoside $\mathrm{Rb} 2(10 \mu \mathrm{M})$ or niacinamide $(100 \mu \mathrm{M})$ or arbutin $(2$ $\mathrm{mM})$ for $24 \mathrm{~h}$. After treatment, the cell extracts $(100 \mu \mathrm{L})$ were mixed with freshly prepared L-DOPA solution ( $0.1 \%$ in PBS), incubated at $37^{\circ} \mathrm{C}$ for $30 \mathrm{~min}$, and the absorbance was measured at $490 \mathrm{~nm}$. After treatment, the cells were lysed in a proteinase inhibitor containing PBS at $4^{\circ} \mathrm{C}$ for 20 min. Proteins $(30 \mu \mathrm{g})$ were resolved by SDS-polyacrylamide gel electrophoresis and electrophoretic ally transferred to a polyvinylidene fluoride (PVDF) membrane. The membrane was blocked in 5\% fat-free milk in PBST buffer (PBS with $0.05 \%$ Tween-20) for $1 \mathrm{~h}$.

After a brief wash, the membrane was incubated overnight at $4^{\circ} \mathrm{C}$ with several antibodies; these antibodies included antiMITF (1:500), anti-TRP1 (1:5000), anti-TRP2 (1:1000), antiMC1R (1:2500), anti-GAPDH (1:2000), anti-tyrosinase (1:1000), and anti-PMEL (1:1000). Following incubation, the membrane was extensively washed in PBST buffer. A subsequent incubation with goat anti-mouse antibody (1:7500) that was conjugated with horseradish peroxidase was conducted at room temperature for $2 \mathrm{~h}$. The blot was visualized using an ECL reagent. The relative amounts of the expressed proteins compared to the total GAPDH content

Table 1: The content of ginsenoside $\mathrm{Rb} 1, \mathrm{Rb} 2$ and $\mathrm{Rg} 3$ in GLF. The data was presented as the mean \pm S.D. of three separate experiments.

\begin{tabular}{|c|c|c|c|}
\hline \multicolumn{3}{|c|}{ Ginsenoside (mg/mL) } \\
\hline Rb 1 & Rb 2 & 522.02 \\
\hline Ginseng & 527.22 & 258.74 & 569.91 \\
\hline Lactobacillus & 585.88 & 221.18 & 555.16 \\
\hline Ferment & 551.06 & 215.12 & 549.03 \\
\hline Average & 554.72 & 231.68 & 20.03 \\
\hline SD & 24.09 & 19.29 & 2 \\
\hline
\end{tabular}

The melanin content was represented as $92.41 \% \pm 0.17 \%$, $87.34 \% \pm 1.23 \%$ and $77.6 \pm 1.21 \%$ of the control for niacinamide $(100 \mu \mathrm{M}), \mathrm{GLF}(0.75 \mathrm{mg} / \mathrm{mL})$ and combination of niacinamide and GLF, respectively (Figure 3C). In (Figure 3D), the melanin content was $92.12 \pm 1.53 \%$ and $83.59 \pm 1.47 \%$ after treatment with niaciamide and $\mathrm{Rb} 2$, respectively. After treatment with combination of the two compounds, the melanin content was $73.06 \pm 2.11 \%$. The results revealed that either GLF or Rb 2 exerted a synergistic inhibitory effect with niacinamide on melanin formation. The cellular tyrosinase activity was $91.01 \pm 0.51 \%$ and $86.13 \pm 0.7 \%$ of the control after $24 \mathrm{~h}$ of niacinamide $(100 \mu \mathrm{M})$ and GLF $(0.75$ $\mathrm{mg} / \mathrm{mL}$ ) treatment, respectively. Further, the cellular tyrosinase activity was $74.89 \pm 1.65 \%$ of the control after treatment with combination of niacinamide and GLF (Figure 3E). Interesting, $\mathrm{Rb} 2$ $(10 \mu \mathrm{M})$ and niacinamide also exerts synergistic inhibitory effect on cellular tyrosinase activity (Figure 3F). The results indicated that were analyzed using Multi Gauge 3.0 software (Fuji, Tokyo). The statistical analysis of the experimental data points was performed by ANOVA, which was used for the comparison of measured data using SPSS 12.0 statistical software (SPSS INC. Chicago, USA). Differences were considered as statistically significant at $p<0.05$.

\section{Results}

The UPLC chromatograms of the GLF are shown in (Figure 1) and the analysis of the ginsenosides in the preparations are represented in (Table 1). The concentration s of ginsenoside $\mathrm{Rb} 1, \mathrm{Rb}$ 2 and Rg 3 in GLF were 554.72 $\pm 24.09,231.68 \pm 19.29$, and 549.03 $\pm 20.03(\mu \mathrm{g} / \mathrm{mL})$, respectively (Table 1$)$. After treatments, the cell viability for the combination of GLF $(0.75 \mathrm{mg} / \mathrm{mL})$ and niacinamide $(100 \mu \mathrm{M})$ was $93.07 \pm 0.56 \%$, whereas the combination of $\mathrm{Rb} 2$ $(10 \mu \mathrm{M})$ and niacinamide was $94.67 \pm 0.74 \%$, compared with that of the control cells. The results indicated that GLF or Rb 2 and niaciamide had no cytotoxic effect on B16F10 cells (Figure 2). The results shown in (Figure 3A) indicated the remaining mushroom tyrosinase activities were $97.22 \pm 1.65 \%, 87.79 \pm 0.55 \%$, and $80.43 \pm 1.16 \%$ of the control for the niacinamide $(100 \mu \mathrm{M}), \mathrm{GLF}$ $(0.75 \mathrm{mg} / \mathrm{mL})$, combination of niacinamide and GLF treatments, respectively. For arbutin ( $2 \mathrm{mM}$ ) and the residual enzyme activities was $70.36 \pm 0.96 \%$ of the control. Similarly, $\mathrm{Rb} 2(10 \mu \mathrm{M})$ exerted synergistic inhibitory effects with niaciamide (Figure 3B). either GLF or Rb 2 exerted a synergistic inhibitory effect on cellular tyrosinase activity with niacinamide.

The expression levels of melanogenesis-related proteins were examined using Western blot. The fold changes of tyrosinase protein expression level compared with the control were $0.98 \pm$ $0.12,0.95 \pm 0.25$ and $0.22 \pm 0.12$ for niacinamide, GLF, combination of niacinamide and GLF, respectively. The fold changes of TRP1 expression levels were $0.94 \pm 0.11,0.91 \pm 0.09$ and $0.85 \pm$ 0.12 for niacinamide, GLF, combination of niacinamide and GLF, respectively. The fold changes of PMEL17 expression levels were $0.95 \pm 0.15,0.87 \pm 0.14$ and $0.72 \pm 0.13$ for niacinamide, GLF, combination of niacinamide and GLF, respectively. (Figure 4A). The results indicated that GLF treatment led to decreased levels of tyrosinase, TRP-1 and PMEL17, and the effects were apparent when combined with niacinamide. Furthermore, the fold changes 
of tyrosinase expression level were $0.97 \pm 0.09,0.92 \pm 0.14$ and $0.18 \pm 0.07$ for niacinamide, $\mathrm{Rb} 2$, combination of niacinamide and $\mathrm{Rb} 2$, respectively. The fold changes of TRP-1 expression levels were $0.95 \pm 0.13,0.89 \pm 0.11$ and $0.82 \pm 0.15$ for niacinamide, $\mathrm{Rb} 2$, combination of niacinamide and $\mathrm{Rb} 2$, respectively. The fold changes of PMEL17 expression levels were $0.96 \pm 0.12,0.83 \pm 0.15$ and 0.70 \pm 0.06 for niacinamide, $\mathrm{Rb} 2$, combination of niacinamide and $\mathrm{Rb} 2$, respectively. (Figure 4B). The results indicated that $\mathrm{Rb} 2$ treatment led to decreased levels of tyrosinase, TRP-1 and PMEL17. The inhibitory effects were synergistically apparent after treatments with niacinamide.

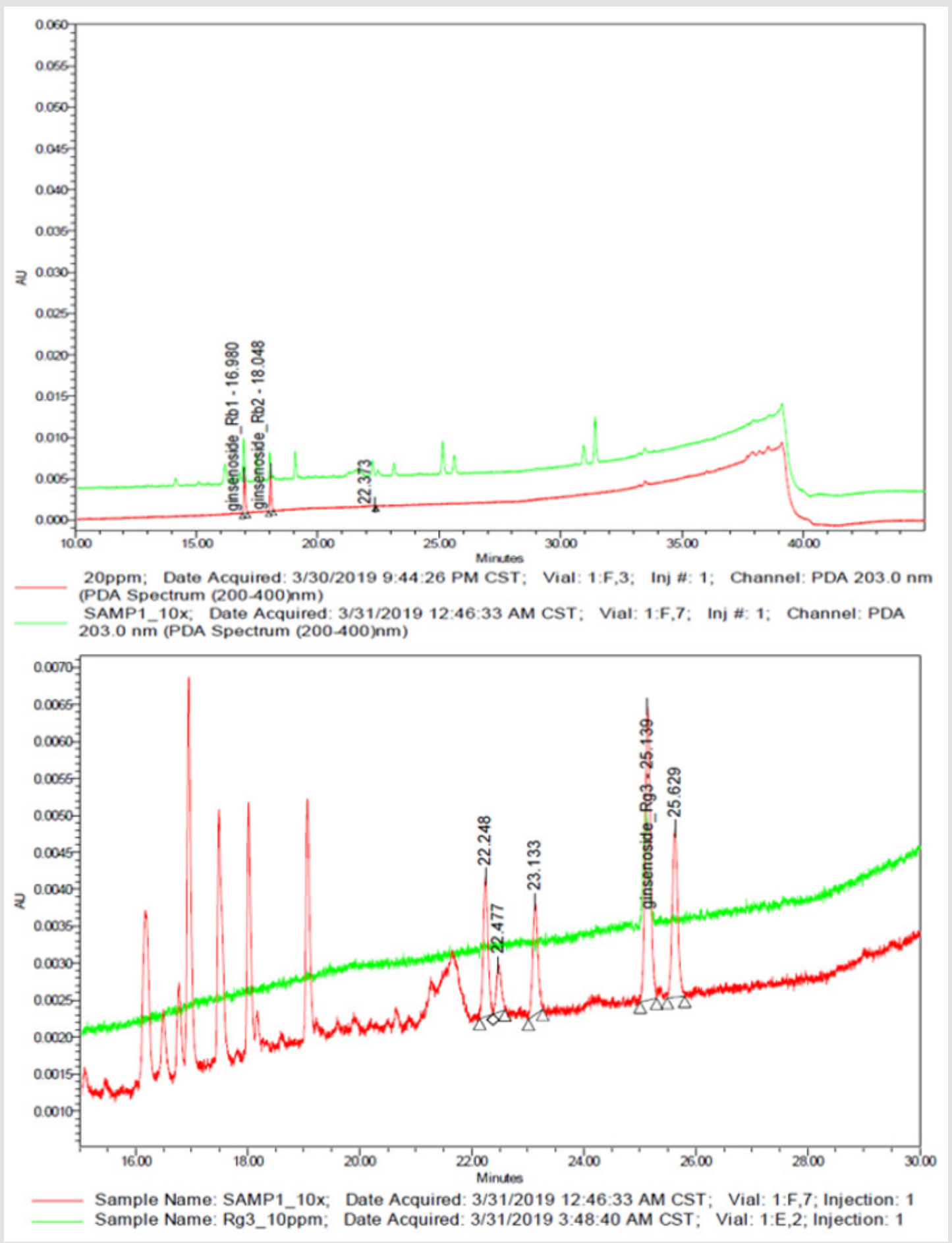

Figure 1: Representative ultra-performance liquid chromatography chromatogram of Panax ginseng lactobacillus ferment (GLF) preparation.

a) Ginsenoside $\mathrm{Rb} 1$ and $\mathrm{Rb} 2$;

b) Ginsenoside $\operatorname{Rg} 3$. 

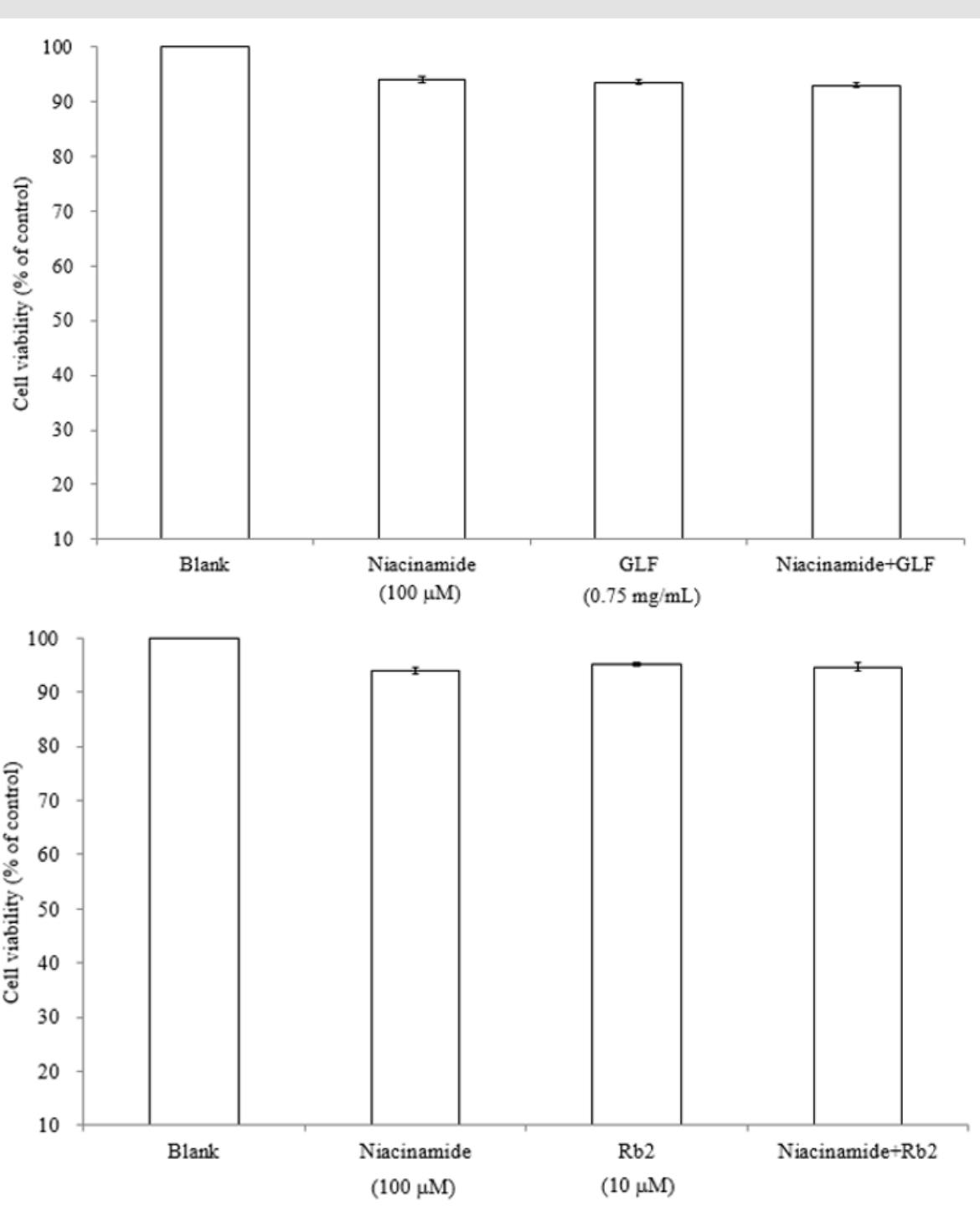

Figure 2: Effects of GLF

a) or $\mathrm{Rb} 2$

b) on the proliferation of B16F10 cells. Cell viability was measured by the MTT assay method after $24 \mathrm{~h}$ of incubation. Data are expressed as a percentage of the number of viable cells observed in the control group, and each column presents the mean values \pm SD from three independent experiments performed in triplicate.

\section{Discussion}

The precision of the developed UPLC method was determined by intra-and inter-day variations. The ginseng lactobacillus ferment (GLF) sample was analyzed as described in the materials and methods sections. There are different ginsenosides in ginseng extract. It has been reported that $\mathrm{Rb} 1[36], \mathrm{Rb} 2$ [28], and $\mathrm{Rg} 3$ [37] exhibit anti-melanogenesis activity. We aim to elucidate which ginsenoside could exert synergistically inhibitory effect on melanogenesis with niacinamide, so we analyzed the content of the three ginsenosides by UPLC (Figure 1). The applications of herbal medicines through adequate compatibility may exert synergistic effects and reduce side effects or drug resistance [38]. The health benefits including prevention of diseases such as cancer can be achieved with increased consumption of vegetables, fruits and botanical dietary supplements containing rich sources of phytochemicals. The action mechanisms by which phytochemicals, including ginsenosides could prevent diseases such as cancer are not clear, but potentially appear to involve the Nrf2-ARE-mediated anti-oxidative stress pathway. In addition, ginseng is often consumed as a mixture comprising various ginsenosides $[39,40]$. 

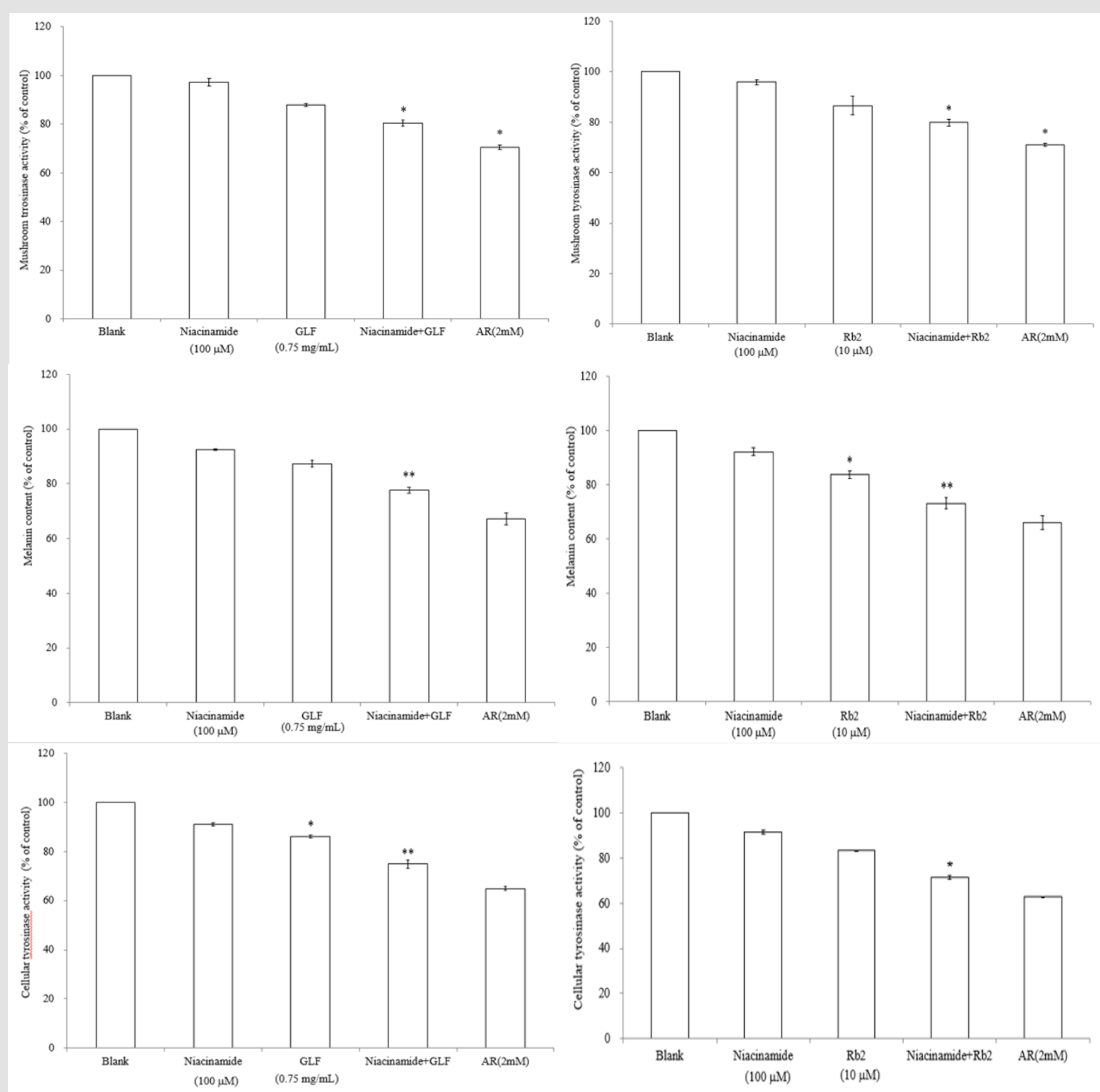

Figure 3: The effects of GLF or ginsenoside Rb 2 on melanogenesis. The effects of GLF

a) or ginsenoside $\mathrm{Rb} 2$

b) on mushroom tyrosinase activity. The effects of GLF

c) or ginsenoside $\mathrm{Rb} 2$

d) on melanin content in the B16F10 cells. .The effects of GLF

e) or ginsenoside $\mathrm{Rb} 2$

f) on cellular tyrosinase activity in the B16F10 cells. The results are presented as percentages of the control, and the data are presented as the means \pm S.D. of three separate experiments. The values are significantly different compared with the control. ${ }^{*} \mathrm{p}<0.05 ;{ }^{* *} \mathrm{p}<0.01$

The MTT assay for cell viability is a colorimetric assay method that is used to measure the activity of NADH/NADPH-dependent cellular oxidoreductase enzymes that reduce MTT to formazan dyes, giving the solution a purple color. The results shown in (Figure 2) indicated that GLF $(0.75 \mathrm{mg} / \mathrm{mL})$ or ginsenoside $\mathrm{Rb} 2(10 \mu \mathrm{M})$ had no cytotoxic effect on B16F10 melanoma cell viability. Mushroom tyrosinase is widely utilized as a target enzyme for screening potential activators or inhibitors of melanogenesis. It was reported that all tyrosinases have a binuclear type three copper center within their active site. However, there was no common tyrosinase protein structure found to occur across all specie [41,42]. Mushroom tyrosinase from Agaricus bisporus was reported to be a soluble 
cytosolic enzyme. In contrast, human tyrosinase is a monomeric membrane-bound glycoprotein. It has been reported that there is no significant correlation between the inhibition of mushroom tyrosinase with human melanoma tyrosinase and melanogenesis [43]. In flavonoids, it has been suggested that anti-tyrosinase activity against mushroom would only appear in parallel with mammalian tyrosinase activity and melanogenesis inhibition [44].

Hence, the structural diversity of the tyrosinase-inhibitory compounds could provide a good source for studying the correlation between enzymatic assay and cell-based assays. In (Figure $3 \mathrm{~A})$, it was shown that niacinamide $(100 \mu \mathrm{M})$ or 0.75 $\mathrm{mg} / \mathrm{mL}$ of GLF alone could not significantly inhibit the activity of mushroom tyrosinase. However, combination of niacinamide (100 $\mu \mathrm{M})$ and GLF ( $0.75 \mathrm{mg} / \mathrm{mL})$ exerted significantly inhibitory effects on mushroom tyrosinase in vitro. Similar synergistic effect was also found in combination of niacinamide $(100 \mu \mathrm{M})$ and ginsenoside $\mathrm{Rb} 2(10 \mu \mathrm{M})$ (Figure 3B). The results shown in (Figure 3C \& 3E) indicated that niacinamide $(100 \mu \mathrm{M})$ and GLF $(0.75 \mathrm{mg} / \mathrm{mL})$ exerts a synergistic inhibitory effect on melanin production and cellular tyrosinase activity, reapectively. The results in (Figure 3D) were in accordance with the results described in (Figure 3F), which means that niacinamide $(100 \mu \mathrm{M})$ and ginsenoside $\mathrm{Rb} 2(10 \mu \mathrm{M})$ synergistically inhibited the B16F10 cellular tyrosinase activity and then decreased the melanin content. The results indicated that ginsenoside $\mathrm{Rb} 2$ may play a role in the synergistic inhibitory effect of GLF and niacinamide on the $\alpha$-MSH-induced melanogenesis in B16F10 cells.
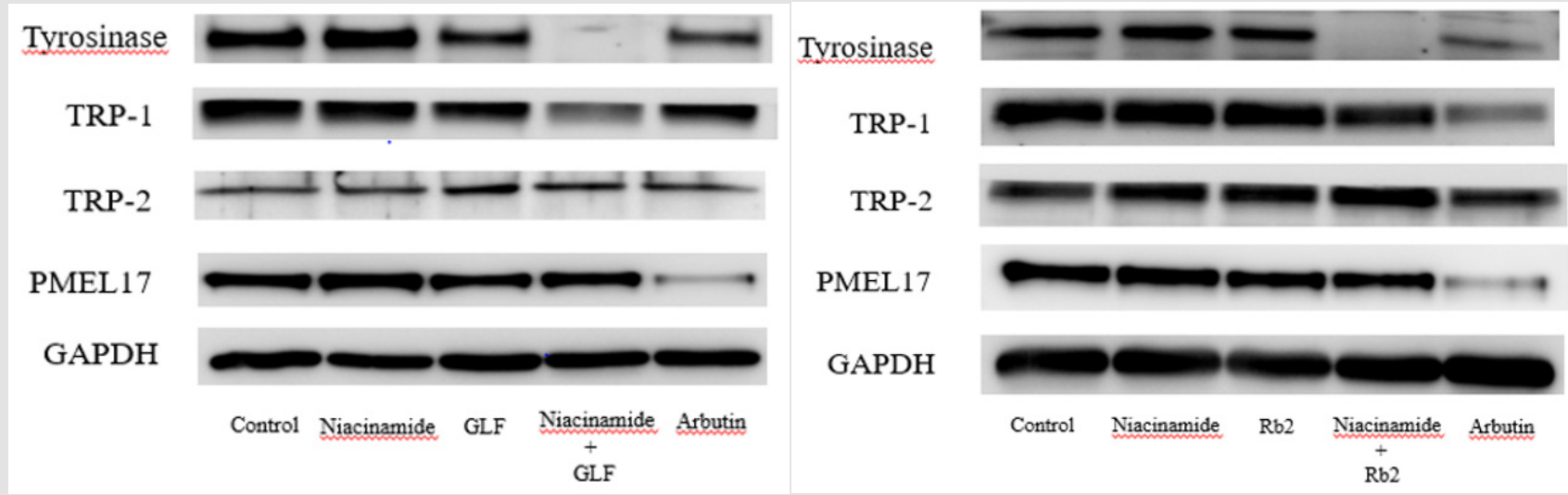

Figure 4: The effects of theophylline on melanogenesis-related protein expression in the B16F10 cells. Western blotting results for tyrosinase, TRP-1, TRP-2 and PMEL17 were shown in (A) GLF and (B) ginsenoside Rb 2.

In the present study, GLF and ginsenoside Rb 2 were observed to inhibit melanogenesis by inhibiting tyrosinase. We hypothesized that the modulation of the melanogenesis-related proteins may be responsible for the inhibitory activity of GLF or ginsenoside $\mathrm{Rb} 2$ on melanogenesis. Hence, the cell lysates were subjected to Western blot analysis to determine the expression levels of melanogenesis-related proteins. In mammals, melanogenesis is regulated by multiple enzymes, such as tyrosinase, TRP-1, TRP-2 and PMEL $[45,46]$. PMEL17 (also known as gp100 or the product of the Silver locus) is a type I integral membrane glycoprotein that localizes to the lumen of melanosome precursors [47-49]. It is highly expressed by melanocytes and serves as a common target for tumor-directed T lymphocytes in patients with melanoma [50]. The results shown in (Figure 4) indicated that GLF or ginsenoside $\mathrm{Rb} 2$ decreased the protein expression levels tyrosinase, TRP-1 and PMEL17. Interestingly, either GLF or ginsenoside $\mathrm{Rb} 2$ exerted antimelanogeic effects synergistically with low dose of niacinamide $(100 \mu \mathrm{M})$.

Hence, the results suggest that the anti-melanogenic activity of
GLF or ginsenoside $\mathrm{Rb} 2$ was probably due to its inhibitory effects on cellular tyrosinase activity and the subsequent decrease in melanin production. The data obtained from this study show that GLF or ginsenoside Rb 2 inhibit melanogenesis in B16F10 melanoma cells without causing cytotoxicity. These findings indicate that combination of GLF or ginsenoside $\mathrm{Rb} 2$ with niacinamide may be useful in treating hyperpigmentation disorders. Furthermore, GLF or ginsenoside $\mathrm{Rb} 2$ and niacinamide could also be used in the formulation of skin whitening products.

\section{Conclusion}

This is the first report on the mechanism of action of the synergistic effect of GLF or ginsenoside Rb 2 with niacinamide on melanin biosynthesis. The present study concluded that GLF or ginsenoside $\mathrm{Rb} 2$ inhibit tyrosinase activity and melanin production in B16F10 cells by declining the expression of tyrosinase, TRP-1 and PMEL17. This finding is of great cosmeceutical importance for the design of skin whiting products that have the potential to reduce hyperpigmentation-related skin cancer risk (Graphic Abstract). 


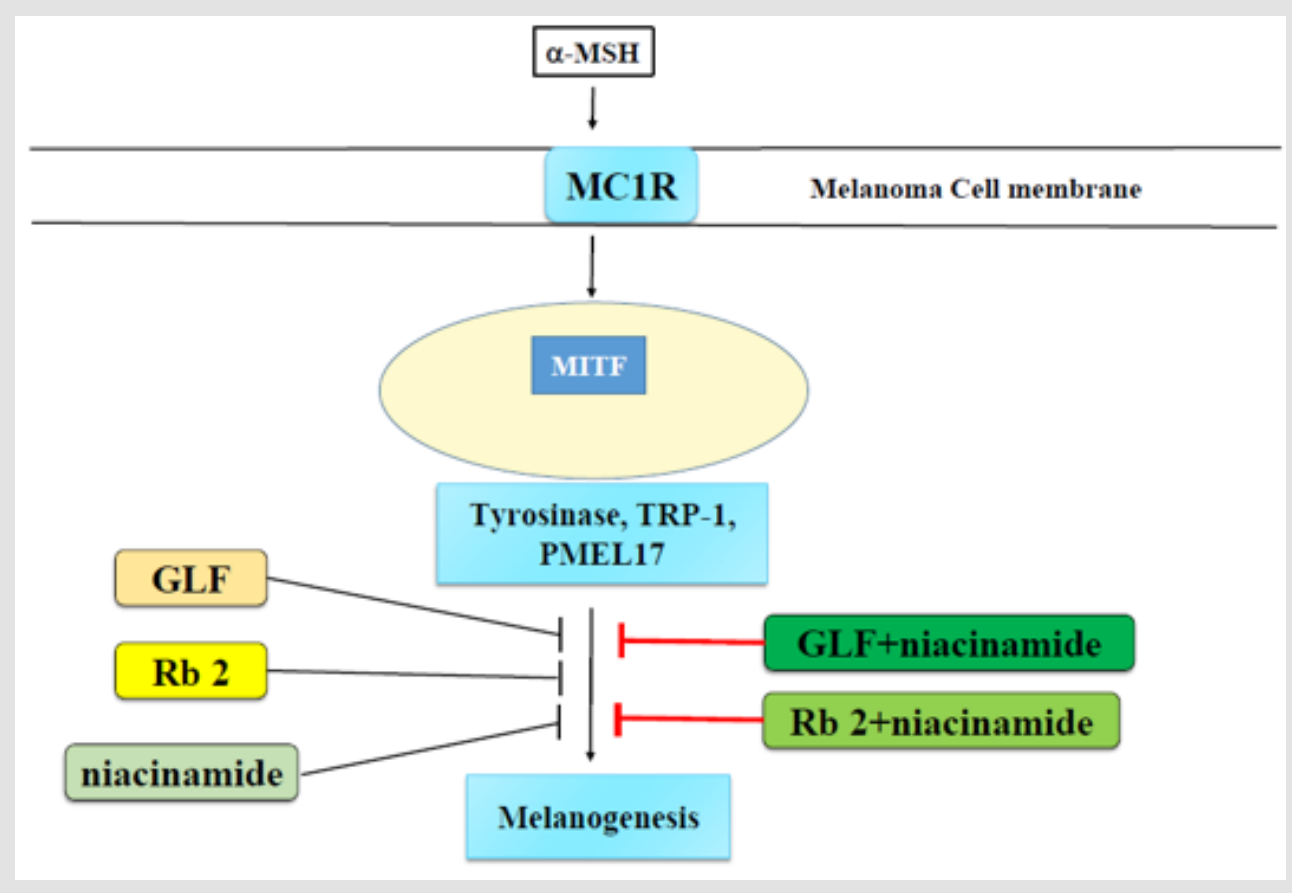

\section{Graphic Abstract}

\section{Author Contributions}

All authors listed, have made substantial, direct and intellectual contribution to the work, and approved it for publication.

\section{Funding}

This research was funded by the Higher Education Sprout Project that was funded by the Ministry of Education (MOE).

\section{Acknowledgments}

This study was financially supported by the Ministry of Science and Technology, under Grant Nos. MOST 108-2314-B-039-050 and MOST 110-2622-8-241-001-TE4.The authors also acknowledge the financial supports by the Higher Education Sprout Project funded by the Ministry of Education (HESP-MOE-HKU-01) and a grant from China Medical University, Taiwan (CMU108-Z-01).

\section{Conflicts of Interest}

The authors declare no conflict of interest. The funders had no role in the design of the study; in the collection, analyses, or interpretation of data; in the writing of the manuscript, or in the decision to publish the results.

\section{References}

1. Martínez Esparza M, Jiménez Cervantes C, Solano F, Lozano JA, García Borrón JC, et al. (1998) Mechanisms of melanogenesis inhibition by tumor necrosis factor- $\alpha$ in B16/F10 mouse melanoma cells. European journal of biochemistry 255(1): 139-146.

2. Leyden J, Shergill B, Micali G, Downie J, Wallo W (2011) Natural options for the management of hyperpigmentation. Journal of the European Academy of Dermatology and Venereology 25(10): 1140-1145.
3. Callender VD, Surin Lord SS, Davis EC, Maclin M (2011) Post inflammatory hyperpigmentation. American journal of clinical dermatology 12(2): 8799.

4. Draelos Z (1999) Cosmetic Consultation: Vitamins and Their Cutaneous Effects. COSMETIC DERMATOLOGY-CEDAR KNOLLS 12(9): 17-22.

5. Elliott RB, Pilcher CC, Fergusson DM, Stewart AW (1996) A populationbased strategy to prevent insulin-dependent diabetes using nicotinamide. J Pediatr Endocrinol Metab 9(5): 501-509.

6. Shalita AR, Smith JG, Parish LC, Sofman MS, Chalker DK (1995) Topical nicotinamide compared with clindamycin gel in the treatment of in elammatory acne vulgaris. International journal of dermatology 34(6): 434-437.

7. Bowes J, Piper J, Thiemermann C (1998) Inhibitors of the activity of poly (ADP-ribose) synthetase reduce the cell death caused by hydrogen peroxide in human cardiac myoblasts. British journal of pharmacology 124(8): 1760-1766.

8. Gensler HL (1997) Prevention of photo immunosuppression and photo carcinogenesis by topical nicotinamide. Nutr Cancer 29(2): 157-162.

9. Tanno O, Ota Y, Kitamura N, Katsube T, Inoue S (2000) Nicotinamide increases biosynthesis of ceramides as well as other stratum corneum lipids to improve the epidermal permeability barrier. British Journal of Dermatology 143(3): 524-531.

10. Wohlrab J, Kreft D (2014) Niacinamide-mechanisms of action and its topical use in dermatology. Skin pharmacology and physiology 27(6): 311-315.

11. Sousa FG, Matuo R, Soares DG, Escargueil AE, Henriques JA, et al. (2012) PARPs and the DNA damage response. Carcinogenesis 33(8): 14331440 .

12. Surjana D, Halliday GM, Damian DL (2013) Nicotinamide enhances repair of ultraviolet radiation-induced DNA damage in human keratinocytes and ex vivo skin. Carcinogenesis 34(5): 1144-1149.

13. Hakozaki T, Minwalla L, Zhuang J, Chhoa M, Matsubara A, et al. (2002) The effect of niacinamide on reducing cutaneous pigmentation and suppression of melanosome transfer. British Journal of Dermatology 147(1): 20-31. 
14. Bissett D, Miyamoto K, Sun P, Li J, Berge C, et al. (2004) Topical niacinamide reduces yellowing, wrinkling, red blotchiness, and hyperpigmented spots in aging facial skin 1 . International journal of cosmetic science 26(5): 231-238.

15. Bissett DL, Oblong JE, Berge CA (2005) Niacinamide: AB vitamin that improves aging facial skin appearance. Dermatologic surgery 31: 860866.

16. Rolfe HM (2014) A review of nicotinamide: Treatment of skin diseases and potential side effects. Journal of cosmetic dermatology 13(4): 324328.

17. Xie J, Wang C, Ni M, Wu J, Mehendale S, et al. (2007) American ginseng berry juice intake reduces blood glucose and body weight in ob/ob mice. Journal of food science 72(8): S590-S594.

18. Wang W, Zhao Y, Rayburn ER, Hill DL, Wang H, et al. (2007) In vitro anticancer activity and structure-activity relationships of natural products isolated from fruits of Panax ginseng. Cancer chemotherapy and pharmacology 59(5): 589-601.

19. Xie JT, Wang CZ, Zhang B, Mehendale SR, Li XL, et al. (2009) In vitro and in vivo anticancer effects of American ginseng berry: exploring representative compounds. Biological and Pharmaceutical Bulletin 32(9): 1552-1558.

20. Shao ZH, Xie JT, Hoek TLV, Mehendale S, Aung H, et al. (2004) Antioxidant effects of American ginseng berry extract in cardiomyocytes exposed to acute oxidant stress. Biochimica et Biophysica Acta (BBA)-General Subjects 1670(3): 165-171.

21. Xie JT, Shao ZH, Hoek TLV, Chang WT, Li J, et al. (2006) Antioxidant effects of ginsenoside Re in cardiomyocytes. European journal of pharmacology 532(3): 201-207

22. Huo YS (1984) Anti-senility action of saponin in Panax ginseng fruit in 327 cases. Zhong Xi Yi Jie He Za Zhi 4(10): 593-596, 578.

23. Bae HM, Cho OS, Kim S J, Im BO, Cho, SH, et al. (2012) Inhibitory effects of ginsenoside re isolated from ginseng berry on histamine and cytokine release in human mast cells and human alveolar epithelial cells. Journal of ginseng research 36(4): 369-374.

24. Lee HJ, Kim SR, Kim JC, Kang CM, Lee YS, et al. (2006) In vivo radioprotective effect of Panax ginseng CA Meyer and identification of active ginsenosides. Phototherapy Research: An International Journal Devoted to Pharmacological and Toxicological Evaluation of Natural Product Derivatives 20(5): 392-395.

25. Lee KT, Jung TW, Lee HJ, Kim SG, Shin YS, et al. (2011) The antidiabetic effect of ginsenoside Rb2 via activation of AMPK. Archives of pharmacal research 34(7): 1201-1208.

26. Sato K, MOCHIZUKI M, SAIKI I, YOO Y, SAMUKAWA K, et al. (1994) Inhibition of tumor angiogenesis and metastasis by a saponin of Panax ginseng, ginsenoside-Rb2. Biological and Pharmaceutical Bulletin 17(5): 635-639.

27. Yoo YC, Lee J, Park SR, Nam KY, Cho YH, et al. (2013) Protective effect of ginsenoside- $\mathrm{Rb} 2$ from Korean red ginseng on the lethal infection of hemagglutinating virus of Japan in mice. Journal of ginseng research 37(1): 80-86

28. Lee DY, Jeong YT, Jeong SC, Lee MK, Min JW, et al. (2015) Melanin biosynthesis inhibition effects of Ginsenoside Rb2 isolated from Panax ginseng Berry. J Microbiol Biotechnol 25(12): 2011-2015.

29. Hugo AA, Bruno F, Golowczyc MA (2016) Whey permeate containing galacto-oligosaccharides as a medium for biomass production and spray drying of Lactobacillus plantarum CIDCA 83114. LWT-food Science and Technology 69: 185-190.

30. Collins J, Ebah C, Mount J, Demott B, Draughon F, et al. (1991) Production and evaluation of milk-sweet potato mixtures fermented with yogurt bacteria. Journal of Food science 56(3): 685-688.

31. Park HW, In G, Han ST, Lee MW, Kim SY, et al. (2013) Simultaneous determination of 30 ginsenosides in Panax ginseng preparations using ultra performance liquid chromatography. Journal of ginseng research 37(4): 457-467.
32. Tada H, Shiho O, Kuroshima K, Koyama M, Tsukamoto K, et al. (1986) An improved colorimetric assay for interleukin 2. Journal of immunological methods 93(2): 157-165.

33. Bilodeau ML, Greulich JD, Hullinger RL, Bertolotto C, Ballotti R, et al. (2001) BMP-2 stimulates tyrosinase gene expression and melanogenesis in differentiated melanocytes. Pigment cell research 14(5): 328-336.

34. Tsuboi T, Kondoh H, Hiratsuka J, Mishima Y (1998) Enhanced melanogenesis induced by tyrosinase gene-transfer increases boronuptake and killing effect of boron neutron capture therapy for amelanotic melanoma. Pigment Cell Res 11(5): 275-282.

35. Yang JY, Koo JH, Song YG, Kwon KB, Lee JH, et al. (2006) Stimulation of melanogenesis by scoparone in B16 melanoma cells. Acta Pharmacol Sin 27(11): 1467-1473

36. Wang L, Lu AP, Yu ZL, Wong RN, Bian ZX, et al. (2014) The melanogenesisinhibitory effect and the percutaneous formulation of ginsenoside Rb1. AAPS PharmSciTech 15(5): 1252-1262.

37. Lee SJ, Lee WJ, Chang SE, Lee GY (2015) Antimelanogenic effect of ginsenoside Rg3 through extracellular signal-regulated kinase-mediated inhibition of microphthalmia-associated transcription factor. Journal of ginseng research 39(3): 238-242.

38. Zhou M, Hong Y, Lin X, Shen L, Feng Y, et al. (2017) Recent pharmaceutical evidence on the compatibility rationality of traditional Chinese medicine. J Ethnopharmacol 206: 363-375.

39. Hu R, Saw CL, Yu R, Kong AN (2010) Regulation of NF-E2-related factor 2 signaling for cancer chemoprevention: Antioxidant coupled with antiinflammatory. Antioxid Redox Signal 13(11): 1679-1698.

40. Khor TO, Yu S, Kong AN (2008) Dietary cancer chemopreventive agents targeting inflammation and Nrf2 signaling pathway. Planta Med 74(13): 1540-1547.

41. Jaenicke E, Decker $H$ (2003) Tyrosinases from crustacean's form hexamers. Biochemical Journal 371(2): 515-523.

42. Mayer AM (2006) Polyphenol oxidases in plants and fungi: going places? A review. Phytochemistry 67(21): 2318-2331.

43. Song TY, Chen CH, Yang NC, Fu CS (2009) The correlation of in vitro mushroom tyrosinase activity with cellular tyrosinase activity and melanin formation in melanoma cells A2058. Journal of Food and Drug Analysis 17(3).

44. Promden W, Viriyabancha W, Monthakantirat O, Umehara K, Noguchi $\mathrm{H}$, et al. (2018) Correlation between the potency of flavonoids on mushroom tyrosinase inhibitory activity and melanin synthesis in melanocytes. Molecules 23(6): 1403.

45. Kameyama K, Sakai C, Kuge S, NISHIYAMA S, Tomita Y, et al. (1995) The expression of tyrosinase, tyrosinase-related proteins 1 and 2 (TRP1 and TRP2), the silver protein and a melanogenic inhibitor in human melanoma cells of differing melanogenic activities. Pigment cell research 8(2): 97-104.

46. Levy C, Khaled M, Fisher DE (2006) MITF: Master regulator of melanocyte development and melanoma oncogene. Trends in molecular medicine 12(9): 406-414

47. Kwon B, Halaban R, Kim G, Usack L, Pomerantz S, et al. (1987) A melanocyte-specific complementary DNA clone whose expression is inducible by melanotropin and isobutylmethyl xanthine. Molecular biology \& medicine 4(6): 339-355.

48. Lee ZH, Hou L, Moellmann G, Kuklinska E, Antol K, et al. (1996) Characterization and subcellular localization of human Pmel 17/silver, a $100-\mathrm{kDa}$ (pre) melanosomal membrane protein associated with 5, 6-dihydroxyindole-2-carboxylic acid (DHICA) converting activity. Journal of Investigative Dermatology 106(4): 605-610.

49. Orlow SJ, Zhou BK, Boissy RE, Pifko Hirst S (1993) Identification of a mammalian melanosomal matrix glycoprotein. Journal of investigative dermatology 101(2): 141-144.

50. Kawakami Y, Robbins PF, Wang RF, Parkhurst M, Kang X, et al. (1998) The use of melanosomal proteins in the immunotherapy of melanoma. Journal of immunotherapy 21(4): 237-246. 
ISSN: 2574-1241

DOI: $10.26717 /$ BJSTR.2020.26.004323

Tsong-Min Chang. Biomed J Sci \& Tech Res

(c) (P) This work is licensed under Creative BY Commons Attribution 4.0 License

Submission Link: https://biomedres.us/submit-manuscript.php

\begin{tabular}{ll} 
BIOMEDICAL & Assets of Publishing with us \\
RESEARCHES & - Global archiving of articles \\
& - Immediate, unrestricted online access \\
\hline hiss: $2574-1241$ & - Rigorous Peer Review Process \\
\end{tabular}

